Article

\title{
The Integration of Vacuum Insulated Glass in Unitized Façade for the Development of Innovative Lightweight and Highly Insulating Energy Efficient Building Envelope-The Results of Eensulate Façade System Design
}

\author{
Alessandro Pracucci *(D), Sara Magnani and Oscar Casadei \\ R\&D Department and Innovation Department, Focchi S.p.A., 47824 Poggio Torriana, Italy; \\ s.magnani@focchi.it (S.M.); o.casadei@focchi.it (O.C.) \\ * Correspondence: a.pracucci@focchi.it; Tel.: +39-335-577-4236
}

Received: 18 August 2020; Accepted: 22 September 2020; Published: 24 September 2020

\begin{abstract}
The European Commission has identified the building industry as one of the key sectors to achieve its 2020 strategy to create conditions for smart, sustainable, and inclusive growth. In this frame, the aim of Horizon 2020's Eensulate project is the development of innovative lightweight and highly insulating energy efficient unitized building façades, suitable for both new and existing buildings. The Eensulate façade module integrates two components developed within the project: Vacuum Insulated Glass (VIG) for architectural purposes, with a $U$-value of $0.3 \mathrm{~W} / \mathrm{sqm} \cdot \mathrm{K}$; a highly insulating foam for automated manufacturing and insulation for the spandrel part. This article presents the Eensulate façade system design simulations and achievements related to VIG integration to solve issues that emerged by the utilization of its innovative components (sealant thermal bridge and getter strips). VIG design and testing have gradually changed the façade module and consequently, façade components have been progressively designed to achieve the expected target of $0.641 \mathrm{~W} / \mathrm{sqm} \cdot \mathrm{K}$ for thermal transmittance. The results demonstrate that the target can be achieved by aluminum profiles, Ethylene Propylene Diene Monomer (EPDM) thermal bridge, and additional insulating components, obtaining a new product for unitized façades able to reduce energy consumption in buildings with large glass surfaces.
\end{abstract}

Keywords: vacuum insulted glass; sealant; unitized façade; glazed building; energy efficiency; lightweight; retrofitting; new construction

\section{Introduction}

In 2010, the European Commission identified the building sector as one of the key sectors to achieve the 2020 strategy of the EU [1,2]. The goal of the 2020 strategy aims at creating conditions for smart, sustainable, and inclusive growth. The European strategies emphasized two key principles-" nearly zero-energy building" and "cost optimality" - that found in legislation issued that member states must ensure so that all new buildings are nearly zero-energy buildings by 31 December 2020. For this purpose, architects, engineers, product developers, and the building industry in general have boosted the development of innovative solutions to reach these targets.

In this scenario, particularly significant is the construction of curtain walls with large glass surfaces. Over recent years, a huge debate has involved actors who operate in buildings with large glass surfaces to assess their impact on sustainability and greenhouse emissions [3-5]. Nowadays, glass building envelopes are the most appreciated solutions for commercial, office, and public buildings and are 
commonly associated with contemporary architecture. However, curtain walls are often criticized for their limited insulation characteristics, while the architectural need is to maximize glass surfaces for aesthetic reasons challenging the poor thermal transmittance of glass in comparison with opaque components. For this reason, glass manufacturers have been developing, in the last 10 years, high performing coatings and solutions for building glass to meet large surfaces for architectural pleasure as well as energy performances [6-9]. Within these innovative products, the manufacturing of Vacuum Insulated Glass (VIG) is particularly significant, with huge investments and results already being confirmed by market applications [10-12]. The expectation of VIG is to contribute to the definitive disruption of glass application in the building sector. The glass market for buildings is today shared between applications of Double Glazed Unit (DGU) with a $U$-value of $1 \mathrm{~W} / \mathrm{sqm} \cdot \mathrm{K}$ and thickness around $28-32 \mathrm{~mm}$ and Triple Glazed Unit (TGU) with a $U$-value of 0.5 and $\mathrm{W} / \mathrm{sqm} \cdot \mathrm{K}$ and a thickness of 40-44 mm [13-15]. VIG aims at achieving a $U$-value of $0.3 \mathrm{~W} / \mathrm{sqm} \cdot \mathrm{K}$ with a thickness of $18 \mathrm{~mm}$. The consequences are remarkable for the façade market and its impact, with a reduction in energy consumption during building operations and reduction in glass load of the façade on bearing structures of the building. In the last 2 years, VIG products have been entering the market, but their adoption by architects, engineering firms, building owners, etc., is becoming slower. The reasons depend on product market barriers (e.g., VIG is not necessary for energy compliance with norms, cost-effectiveness) as well as actors' expectations (e.g., durability, performances, dimensions). Additionally, VIG application in a façade system needs to be compliant with the overall thermal requirements and façade norms to demonstrate its potential as well as limitations for its adoption.

In this context, the European Horizon 2020 project "Eensulate" [16], started in 2016, has the purpose to design, test, and prototype in real environment applications an Eensulate unitized façade, which integrates an innovative VIG, manufactured through a low temperature process using polymeric flexible adhesives (sealant) and distributed getter technology. The Eensulate façade module will be designed to integrate the VIG developed in the Eensulate project, demonstrating its applicability as well as its replicability at an industrial scale. In addition, the Eensulate façade module here presented integrates another innovative component developed within the project, a highly insulating mono-component foam for the cost-effective automated manufacturing and insulation of the opaque components of the façade. Initially, the Eensulate façade system design was implemented facing the weak points step by step and providing an optimized designed for the final configuration of the Eensulate façade system. The result is a façade solution that meets the industrial needs for massive use and wide replication in the market. The purpose of this paper is to demonstrate the applicability of VIG and the thermal transmittance achievable in the Eensulate façade system design, analyzing its development along the different project phases and comparing the quantitative performance achieved with the targets expected by the project. For each step, a two-dimensional thermal transmittance analysis was conducted, underlining the issues that emerged and the further steps to be taken on the base of single component development.

\section{Materials and Methods}

\subsection{Eensulate Materials}

Differently from a standard architectural-driven design process, the Eensulate module is a technologically driven façade. Indeed, the specific needs of the project technologies-foam and VIG, in particular-have required continuous improvement of the façade system design to meet the specific progress achieved by technological components development.

In the design phase, the main component to be integrated and implemented in the Eensulate façade system is the VIG. While the foam can be integrated in the system as a traditional insulation, guaranteeing higher thermal performances but requiring to face acoustic issues (not the object of this article), the VIG requires specific developments due to its composition, thermal, and aesthetic appeal.

The following elements have been considered in the Eensulate façade system design [17]: 
- Eensulate VIG:

Technical characteristics-two panes of $6 \mathrm{~mm}$ thick fully tempered glass using a combination of uncoated and soft low-E coated glass. Based on modelling results, an array of stainless-steel support pillars, $0.4 \mathrm{~mm}$ in diameter, $0.2 \mathrm{~mm}$ high, and spaced on a $50 \mathrm{~mm}$ regular grid, maintains the separation of the glass panes. The target expected by the project is a $U$-value of $0.3 \mathrm{~W} / \mathrm{sqm} \cdot \mathrm{K}$ at the ultimate vacuum pressure after evacuation of $5 \mathrm{e}-6 \mathrm{mbar}$, with a guaranteed lifetime of 20 years through a vacuum level lower than 1e-3mbar. The result achieved in a small scale prototype $(500 \times 500 \mathrm{~mm})$ is a center-of-pane $U$-value of $0.36 \mathrm{~W} / \mathrm{sqm} \cdot \mathrm{K}$ and an overall $U$-value of $0.44 \mathrm{~W} / \mathrm{sqm} \cdot \mathrm{K}$. As the test is already ongoing, the reference for the simulation is a $U$-value of $0.3 \mathrm{~W} / \mathrm{sqm} \cdot \mathrm{K}$.

- Sealant dimension - the sealant (innovative component of Eensulate's VIG) guarantees the adhesion between the glass panes, but it is a thermal bridge to be considered. Its dimension has changed during VIG development from 15 to $25 \mathrm{~mm}$, affecting the Eensulate façade system design.

Sealant and getter position - their dimension (sealant is $15-25 \mathrm{~mm}$ and getter is a strip of $8 \mathrm{~mm}$ ) and their position in the VIG are aesthetic issues to be faced to guarantee architectural appraisal of the Eensulate façade.

- Pumping hole position-necessary to pump out the air during vacuum creation; its position is an aesthetic issue to be faced.

- Laminated glass-a lamination is needed for safe installation of the façade and to avoid falling risk in case of glass breakage. For this purpose, an additional pane of $6 \mathrm{~mm}$ of Heat Strengthened (HS) glass has been included.

- Eensulate foam:

- Technical characteristics-Two Component Foam (TCF) is highly insulating polyisocyanurate (PIR) foam-based insulating material enhanced with eco-friendly lamellar inorganic fillers. TCF is used to be injected and is workable for manufacturing. The advantages of the TCF system during the production system are the increased efficiency of $35 \mathrm{~kg} / \mathrm{cm}$ and ease of processing. The $U$-value is $0.024 \mathrm{~W} / \mathrm{sqm} \cdot \mathrm{K}$.

\subsection{Methods}

The present chapter synthetizes the key elements of the methodology adopted to develop the Eensulate façade system.

1. Identification of preliminary boundary conditions:

a. Preliminary design solution-starting from preliminary design outputs set as in the early phase of the project, the Eensulate façade system design was implemented with the information and results during VIG and foam development. The preliminary design defined a U-value target for the unit with an Eensulate façade module dimension of $1500 \times 3500 \mathrm{~mm}$ as $0.586 \mathrm{~W} / \mathrm{sqm} \cdot \mathrm{K}$ for VIG with $15 \mathrm{~mm}$ of sealant (thermal bridge) and using structural silicone, and as $0.641 \mathrm{~W} / \mathrm{sqm} \cdot \mathrm{K}$ for VIG with $25 \mathrm{~mm}$.

b. Market benchmark-identification of components, especially profiles, to be used in the Eensulate module. In addition, the identification of the current façade market benchmark with a similar U-value to the Eensulate façade module has been investigated.

c. Safety issue-despite all the necessary solutions having been adopted to guarantee a safety installation of VIG, the behavior of the VIG under stress conditions needs further investigation. For this reason, the Eensulate façade system has not been designed for structural silicone as expected in preliminary design activities, but with a glazing bead for VIG restraint that has been introduced, causing an additional thermal bridge in the module that affects the thermal 
behavior of the whole Eensulate façade system. The consequence is an improvement of the thermal bridge, an issue to be faced during the design phase.

2. Eensulate module design and optimization:

a. Façade engineering design - the U-value expected by the project was defined for a façade unit of $1500 \times 3500 \mathrm{~mm}$. However, the building demonstrator to validate the Eensulate façade in a real environment is a school in Dzierżoniów, Poland (Figure 1), which has been used to size the unit of reference. The school built in the 1980s has a façade object of intervention in the Eensulate project of $90 \mathrm{sqm}$, realized with a stick system with an estimated U-value $>3.5 \mathrm{~W} / \mathrm{sqm} \cdot \mathrm{K}$. On the base of the existing school's façade, the unit dimension considered as the reference (the school in Dzierżoniów, Poland) is $1261 \times 3640 \mathrm{~mm}$ (Figure 2); this dimension has been considered the reference to achieve the U-value target for real dimensions. As the aluminum profile's U-value is worse than the VIG's U-value, this choice is more negative to pursue the planned target because the U-value of VIG (lower than the aluminum profile) has a lower incidence. Additionally, the key elements to be considered and balanced in façade engineering are:

i. Thermal performances - from $0.586 \mathrm{~W} / \mathrm{sqm} \cdot \mathrm{K}$ (sealant $15 \mathrm{~mm}$ ) to $0.7 \mathrm{~W} / \mathrm{sqm} \cdot \mathrm{K}$ (sealant $25 \mathrm{~mm}$ ) is the target of the project.

ii. Performances of the façade-compliance with UNI EN 13830:2005 to obtain CE on the façade.

iii. Acoustic performance- $52 \mathrm{~dB}$ of insulation.

iv. Replacement strategy - in case of VIG failure because of shorter durability in relation to the planned lifespan expectation of 20 years.

b. Façade architectural design—requests emerged from the architect and building demonstrator owner to balance the aesthetical appraisal of the Eensulate module and homogenize the façade with already existing solutions in the building (glazing beads and colors in the current façade configuration, Figures 3 and 4).

3. Identification of pitfalls:

a. Scalability-design and prototyping direct the identification of the eventual pitfalls necessary to support the scale up of the Eensulate façade's components for their application in the façade system.

b. Industrialization-design and prototyping direct the identification of the eventual pitfalls to industrialize the Eensulate façade supporting massive use and wide replication.

In this design methodology, the significant simulation step is the $U$-value assessment. The calculation has been conducted in accordance with NI EN ISO 10077-2 and ISO 10456:2008, using as software THERM 7, developed and validated by Lawrence Berkeley National Laboratory (US Department of Energy). The $U$-value was calculated on the base of the facade system designed in CAD software with a joint and glass portion of $190 \mathrm{~mm}$, and then was imported into THERM where each material was defined with its technical characteristics as well as boundary conditions. The THERM software requires the following data:

- Thermal properties of the materials;

- Cold-side environmental temperature;

- Cold-side surfaces thermal resistance;

- Warm-side environmental temperature;

- Warm-side surfaces thermal resistance.

The following environmental data are assumed (Table 1): (see UNI EN ISO 10077-2). 
Table 1. Environmental data assumed by UNI EN ISO 10077-2.

\begin{tabular}{ccc}
\hline Element & Initial & Data \\
\hline Outside temperature & $\mathrm{Te}$ & $0{ }^{\circ} \mathrm{C}$ \\
Outside heat transfer coefficient & $\mathrm{he}$ & $25 \mathrm{~W} / \mathrm{sqm} \cdot \mathrm{C}$ \\
Inside temperature & $\mathrm{Ti}$ & $+20{ }^{\circ} \mathrm{C}$ \\
Inside heat transfer coefficient & $\mathrm{hi}$ & $7.69 \mathrm{~W} / \mathrm{sqm} \cdot \mathrm{C}$ \\
Inside heat transfer coefficient reduced & $\mathrm{hir}$ & $5 \mathrm{~W} / \mathrm{sqm} \cdot \mathrm{C}$ \\
\hline
\end{tabular}

The curtain wall heat loss assessment consists of the specific analysis of the window bay's main section. Each analysis provides the U-factor for a section. This $U$-value refers to the projected area of the section itself.

Thermal transmittance of the thermal joint, $\mathrm{U}_{T J}$, is defined as follows.

$$
\mathrm{U}_{T J}=\frac{\Phi_{T J}}{A_{T J} \cdot \Delta T}
$$

Total heat flow rate $\Phi_{T O T}$ of the complete connection is calculated using computer software that conforms to EN ISO 10211 and EN ISO 10077-2.

In accordance with EN 12631 "Single assessment method-Area Related thermal transmittance":

$$
\Phi_{T J}=\Phi_{T O T}-\sum\left(\mathrm{U}_{F E} \cdot A_{F E}\right) \cdot \Delta T
$$

where:

$\mathrm{U}_{T j}$ thermal transmittance of thermal joint (node), in $\mathrm{W} / \mathrm{sqm} \cdot \mathrm{K}$;

$\Phi_{T J}$ heat flow rate of thermal joint, in $\mathrm{W} / \mathrm{m}$;

$\mathrm{U}_{F E}$ thermal transmittance of filling element (glazing, spandrel), in $\mathrm{W} / \mathrm{sqm} \cdot \mathrm{K}$;

$A_{T J}$ projected area of thermal joint, in m;

$A_{F E}$ projected area of filling element, in m;

$\Phi_{T O T}$ total heat flow rate of section, in $\mathrm{W} / \mathrm{m}$.

Following the methodology here presented, this article reports the main achievements and further steps suggested to meet the marketability of the Eensulate façade system.
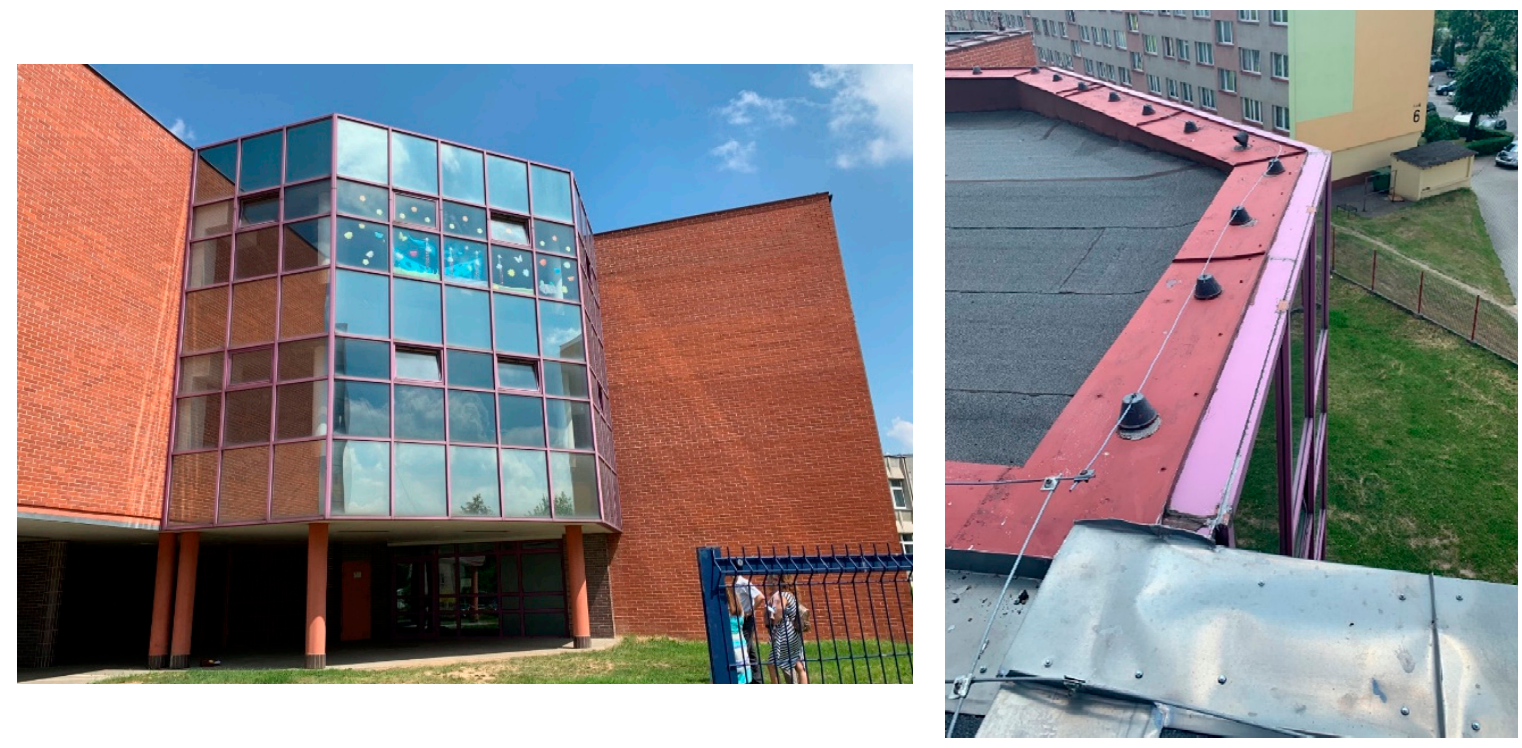

Figure 1. The existing façade to be renovated in Dzierżoniów School, Poland. 


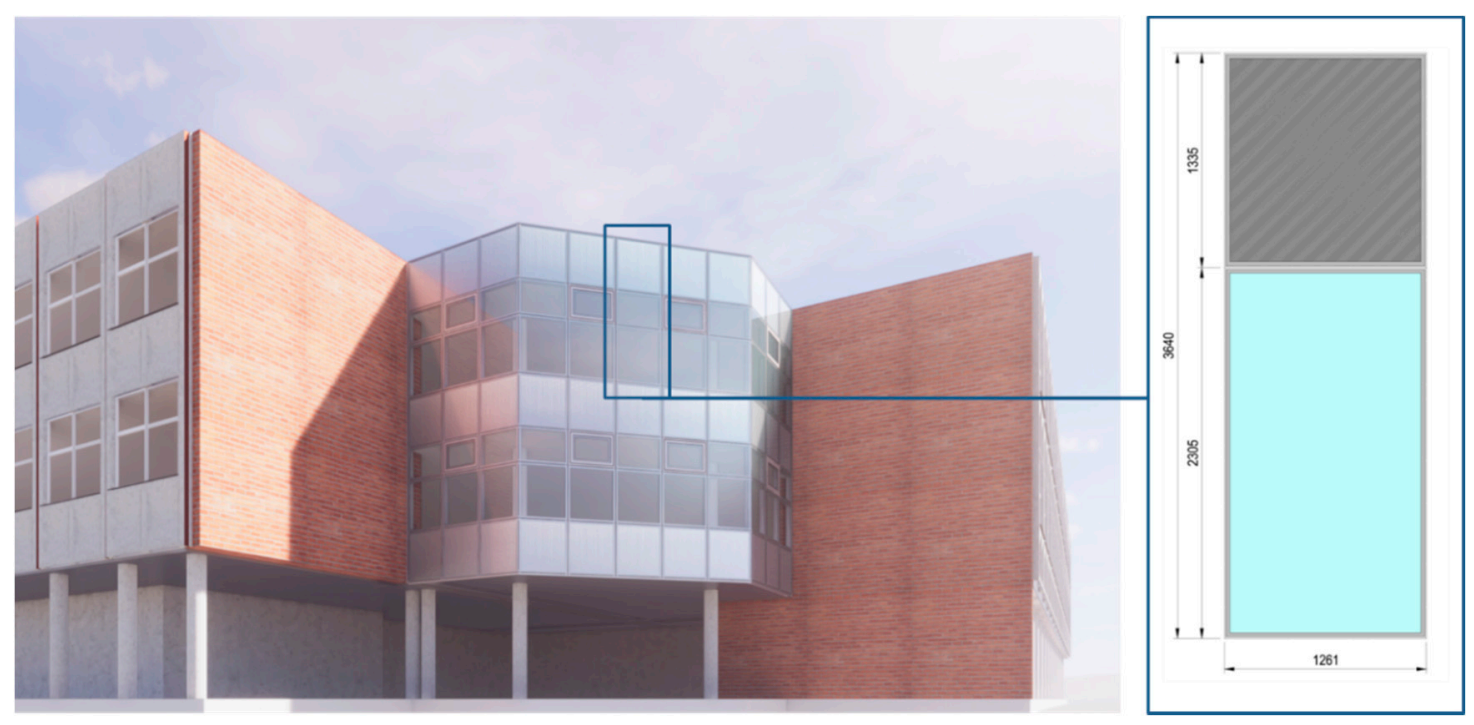

Figure 2. Eensulate module: the reference dimension $1261 \times 3640$ is based on the first survey conducted on Dzierżoniów School.
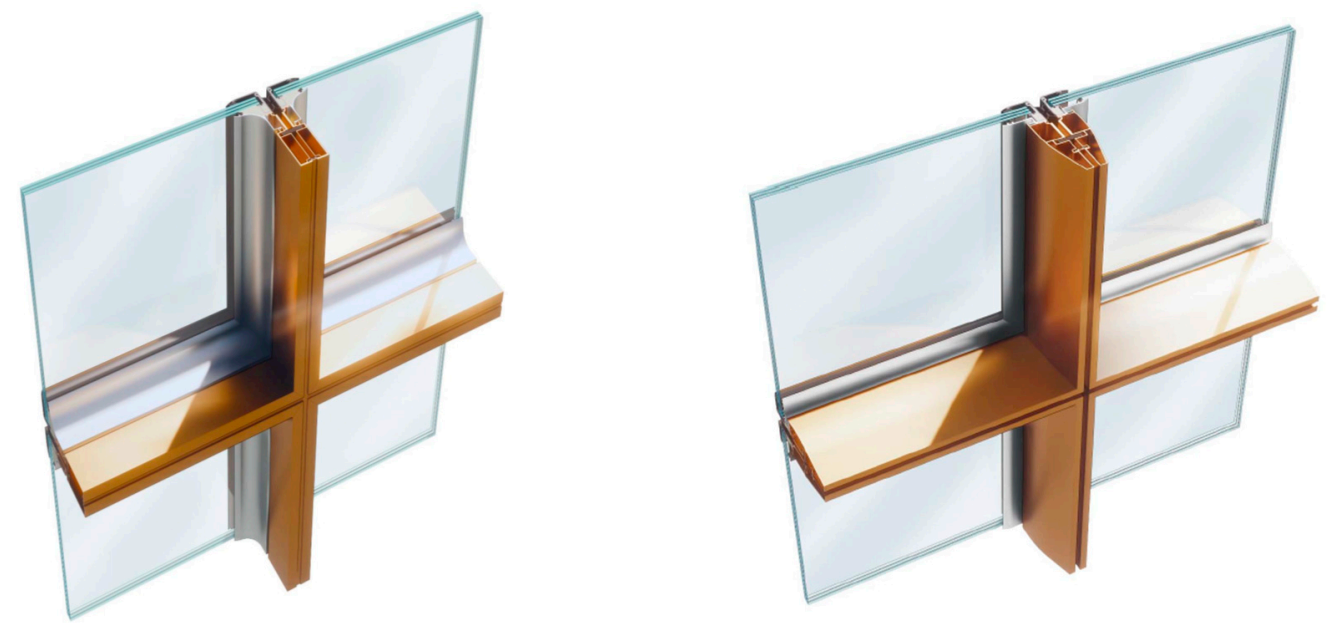

Figure 3. Eensulate module shape design for Dzierżoniów School (credit: UNSTUDIO).
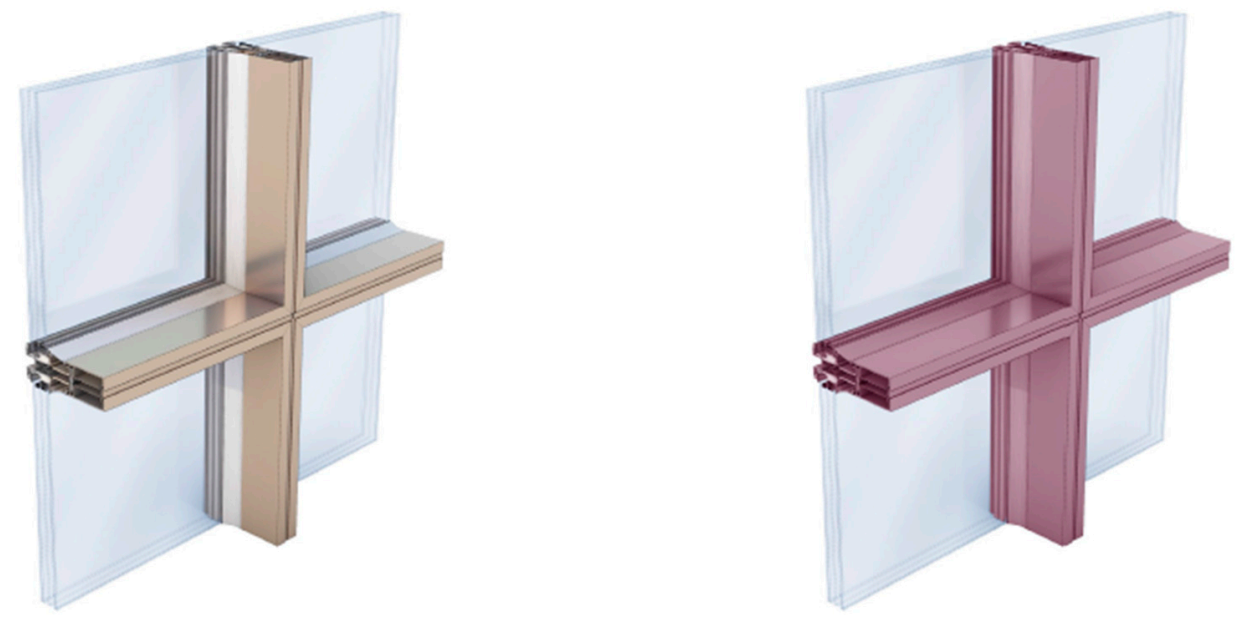

Figure 4. Eensulate module color analysis for Dzierżoniów School (credit: UNSTUDIO). 


\section{Results}

\subsection{Eensulate Facade System: 1st Solution}

The 1st solution of the Eensulate module has been designed taking into consideration the utilization of a market profile and VIG's sealant of $15 \mathrm{~mm}$ (Figure 5). Since the very early phase, the thermal bridge caused by the sealant and its meaningful dimension has been identified as a critical point. For this reason, in the profile, an insulating material (preformed element to be inserted in the profile) has been introduced to pursue the Eensulate module target expected to be achieved.

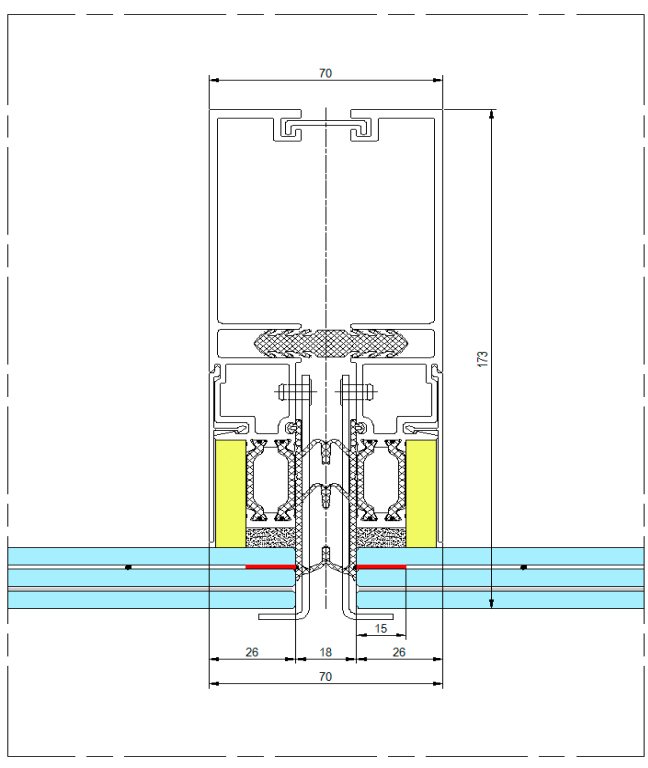

(a)

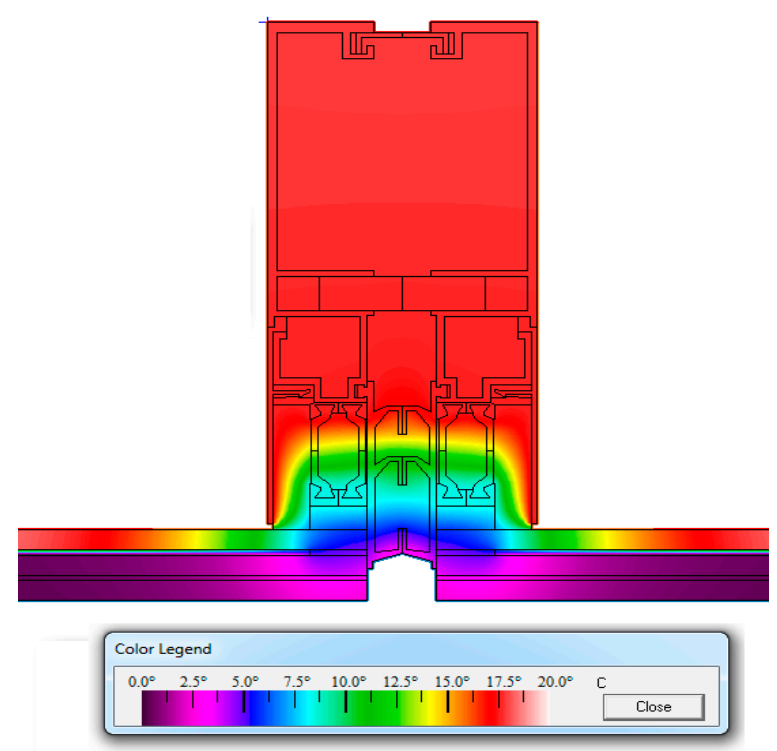

(b)

Figure 5. Eensulate facade system: 1st solution. (a) The Eensulate module is designed with commercially available profiles. (b) Thermal assessment. The thermal bridge due to sealant identifies critical points of the system.

The thermal analysis (Figure 5b) shows that the well-known pitfall of the thermal bridge is a critical point, which needs further study to decrease its incidence on the façade system.

The $\mathrm{U}_{T J}$ does not allow the accomplishing of the target thermal transmittance for the Eensulate module, which achieves a $U$-value of $0.79 \mathrm{~W} / \mathrm{sqm} \cdot \mathrm{K}$ (Table 2 ).

Table 2. Eensulate facade system: 1st solution. Key points of the solution.

\begin{tabular}{cccc}
\hline Solutions Adopted & Issues Emerged & $\begin{array}{c}\text { Thermal Transmittance } \\
\text { Achieved }\end{array}$ & Target \\
\hline Sealant $15 \mathrm{~mm}$ & $\begin{array}{c}\text { Thermal bridge } \\
\text { Sealant to } 15 \mathrm{~mm}\end{array}$ & $0.79 \mathrm{~W} / \mathrm{sqm} \cdot \mathrm{K}$ & $\begin{array}{c}0.586 \mathrm{~W} / \mathrm{sqm} \cdot \mathrm{K} \\
\text { (sealant to } 15 \mathrm{~mm} \text { ) }\end{array}$ \\
\hline
\end{tabular}

\subsection{Eensulate Facade System: 2nd Solution}

Starting from the 1st Eensulate module design and thermal bridge issue that emerged, the 2nd solution was designed with a profile with a cover-cap plus insulating material to reduce the thermal bridge caused by the $15 \mathrm{~mm}$ of VIG sealant (Figure 6). 


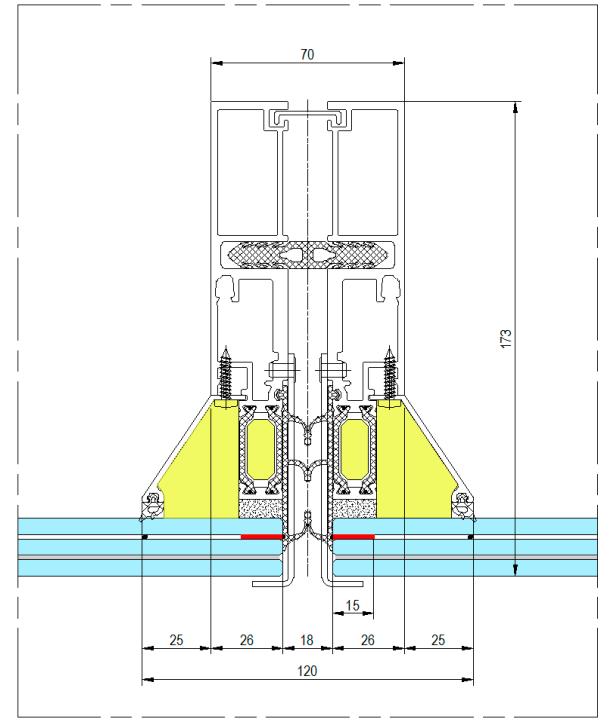

(a)

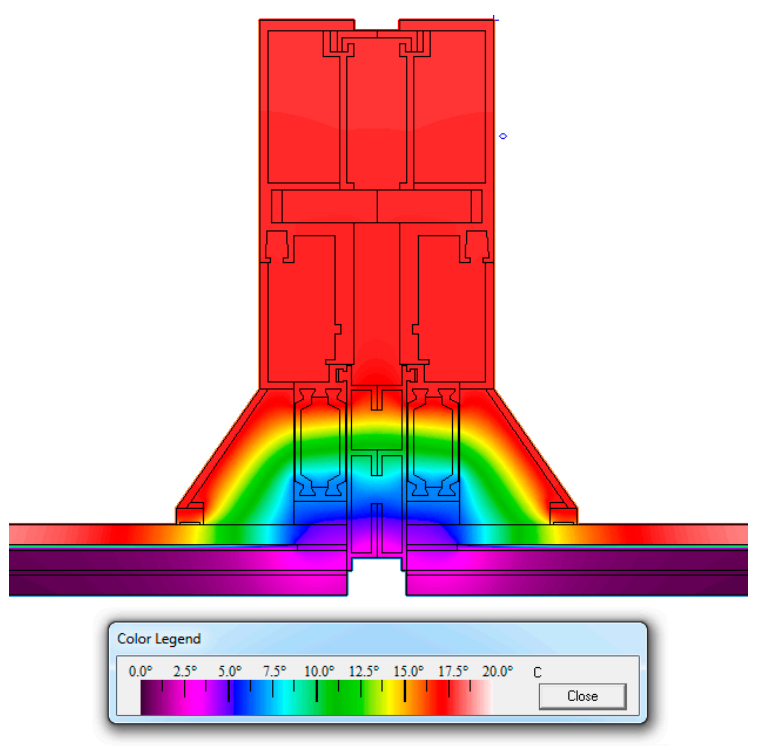

(b)

Figure 6. Eensulate facade system: 2nd solution. (a) The Eensulate module is designed with a new profile to reduce thermal bridge. (b) Thermal assessment. The thermal bridge of the 1st solution is reduced, but an aesthetical issue emerges.

The solution as designed demonstrates the effectiveness of this new profile with cover-cap and insulating material. Indeed, the overall thermal transmittance of the Eensulate module achieves $0.58 \mathrm{~W} / \mathrm{sqm} \cdot \mathrm{K}$ (Table 3).

Table 3. Eensulate facade system: 2nd solution. Key points of the solution.

\begin{tabular}{cccc}
\hline Solutions Adopted & Issues Emerged & $\begin{array}{c}\text { Thermal Transmittance } \\
\text { Achieved }\end{array}$ & Target \\
\hline $\begin{array}{c}\text { Profile design for } \\
\text { thermal reason }\end{array}$ & $\begin{array}{c}\text { Profile design for aesthetic issue } \\
\text { Sealant to } 15 \mathrm{~mm}\end{array}$ & $0.58 \mathrm{~W} / \mathrm{sqm} \cdot \mathrm{K}$ & $\begin{array}{c}0.586 \mathrm{~W} / \mathrm{sqm} \cdot \mathrm{K} \\
\text { (sealant to } 15 \mathrm{~mm} \text { ) }\end{array}$ \\
\hline
\end{tabular}

However, this design requires further improvement due to aesthetical reasons. For this purpose, a further design implementation is needed.

\subsection{Eensulate Facade System: 3rd Solution}

From the 2nd design solution, the 3rd solution introduces an aesthetical improvement with a new curved cover-cap to connect the VIG surface and aluminum profile (Figure 7). Despite this solution providing a better aesthetic result, there is a worsening of $U$-value achieved by the Eensulate module with $0.62 \mathrm{~W} / \mathrm{sqm} \cdot \mathrm{K}$.

Despite this value possibly being considered not acceptable with the $15 \mathrm{~mm}$ sealant (target was $0.586 \mathrm{~W} / \mathrm{sqm} \cdot \mathrm{K}$ ) and being needed for further development, another issue emerged during VIG design: for air tightness reasons, the VIG sealant had to be $25 \mathrm{~mm}$, with a consequent increase in thermal bridge. This change needed, for further updates, to have a high performing energy system; the expected thermal transmittance target is $0.641 \mathrm{~W} / \mathrm{sqm} \cdot \mathrm{K}$ for VIG with $25 \mathrm{~mm}$ of sealant (Table 4). 


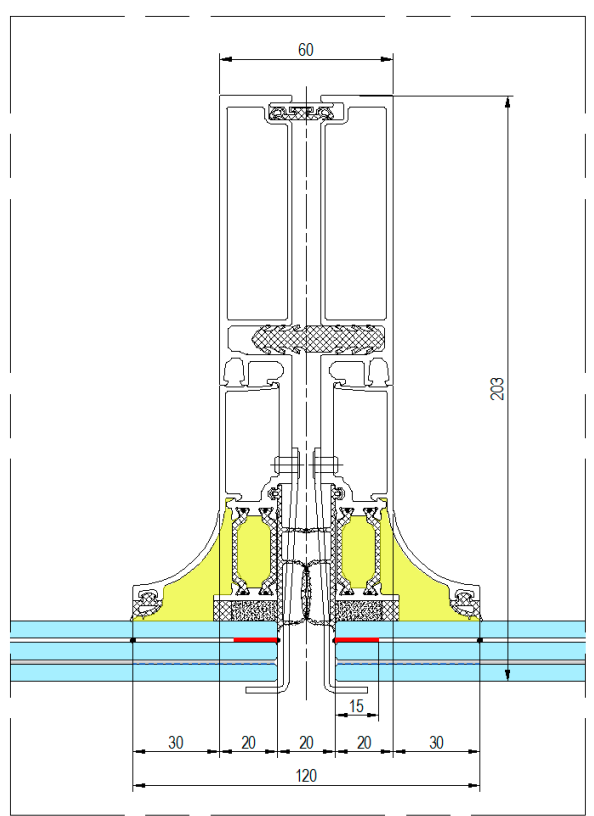

(a)

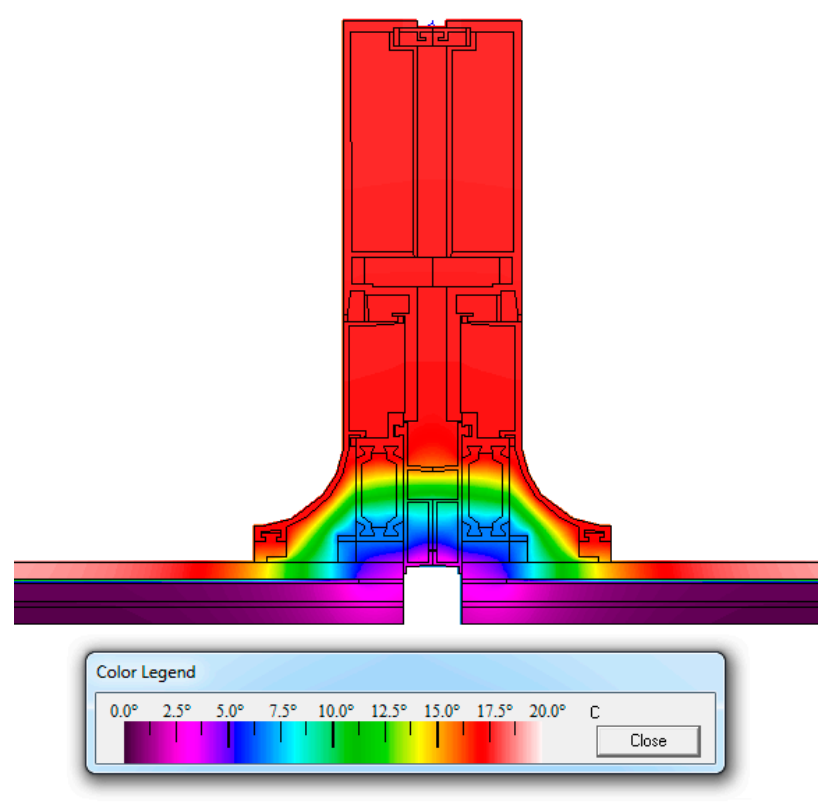

(b)

Figure 7. Eensulate facade system: 3rd solution. (a) The Eensulate module is designed with a new curved cover-cap. (b) Thermal assessment. The profile adopted uses a curved profile to meet aesthetical appraisal of the module.

Table 4. Eensulate facade system: 3rd solution. Key points of the solution.

\begin{tabular}{cccc}
\hline Solutions Adopted & Issues Emerged & $\begin{array}{c}\text { Thermal Transmittance } \\
\text { Achieved }\end{array}$ & Target \\
\hline $\begin{array}{c}\text { Curved profile for aesthetic } \\
\text { and thermal reasons }\end{array}$ & Sealant to $15 \mathrm{~mm}$ & $0.62 \mathrm{~W} / \mathrm{sqm} \cdot \mathrm{K}$ & $\begin{array}{c}0.586 \mathrm{~W} / \mathrm{sqm} \cdot \mathrm{K} \\
\text { (sealant to } 15 \mathrm{~mm} \text { ) }\end{array}$ \\
\hline
\end{tabular}

\subsection{Eensulate Façade System Optimization}

\subsubsection{Investigation of Pultruded Profiles}

Different issues emerged and the willingness to keep improving the thermal transmittance of the overall Eensulate module directed further investigations for the design improvement of the Eensulate façade system. In particular, the focus has been to identify a node solution (profile-VIG) able to contain thermal loss through the opportunity to use pultruded material. Some scenarios of pultruded solutions have been thermally analyzed:

- $\quad$ Eensulate façade system-pultruded 1-25 mm sealant, pultruded profile, aluminum glazing bead.

- Eensulate façade system-pultruded 2-25 mm sealant, pultruded profile, pultruded glazing bead (Figure 8).

Among the solutions evaluated, the simulation shows a $U$-value $<0.641 \mathrm{~W} / \mathrm{sqm} \cdot \mathrm{K}$ only in the case of the Eensulate façade system-pultruded 2, the solution with pultrusion for both the frame and glass bead.

Despite this solution seeming valuable according to thermal analysis, the utilization of pultrusion would have caused some critical issues for scalability and industrialization of the façade. Indeed, this material, despite the important thermal property, is not considered a market ready product for the façade market because of the cost and time of procurement, crucial for the industrialization phase. These reasons have been addressed in the final Eensulate façade system solution, another step of investigation using new profiles for both the aluminum frame as well as for the polyamide profile. 

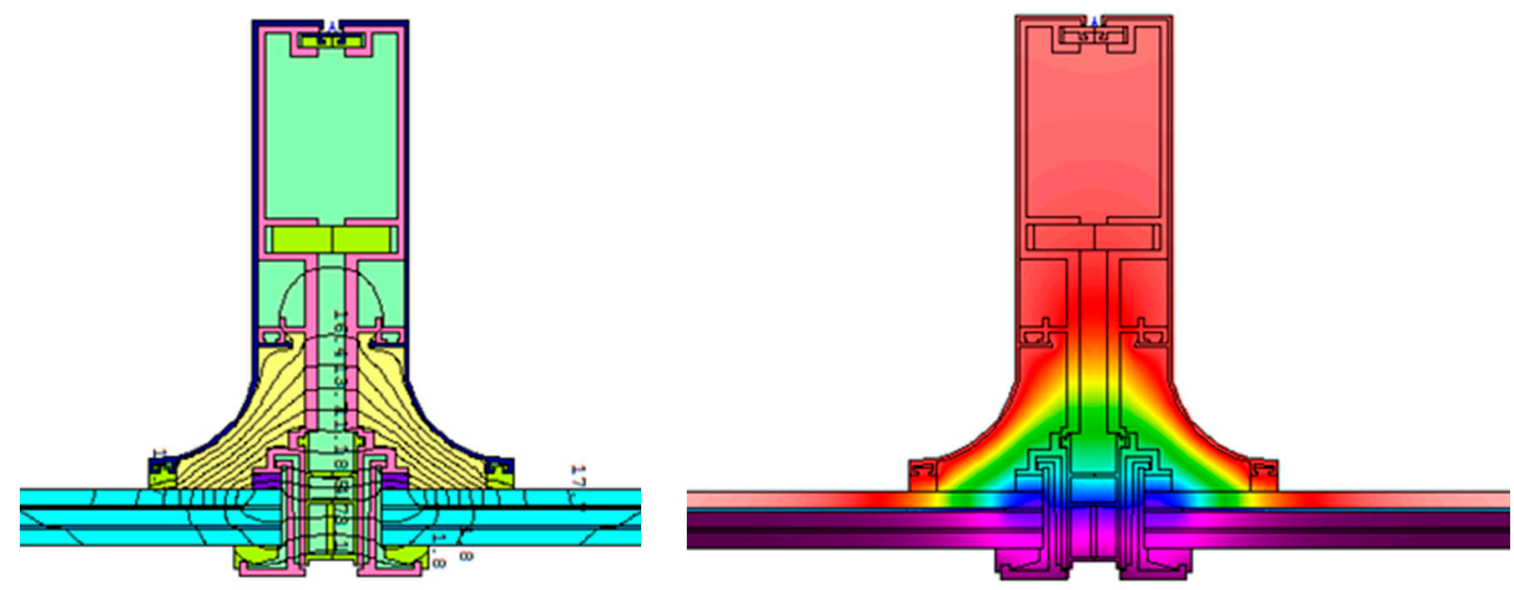

Figure 8. Eensulate facade system with pultruded profile solution.

\subsubsection{Architectural and Demo Requirements}

In addition to designing and manufacturing new profiles, the final design has also been addressed in relation to architectural reasons. Even if the Eensulate façade system is mainly driven by Eensulate technologies, the relationship between engineering and architectural issues guarantees an improvement able to be market responsive. For this reason, many concerns have been faced: profile shapes, cover-cap shapes, glazing bead dimension and shapes (Figure 9), and colors to be used (Figures 10 and 11). All these architectural observations have been shared among the partners involved in this process (Focchi and Unstudio [18]) and evaluated for their applicability. The result achieved by the Eensulate façade system is a synthesis of the aspects adopted and the discarded ones.
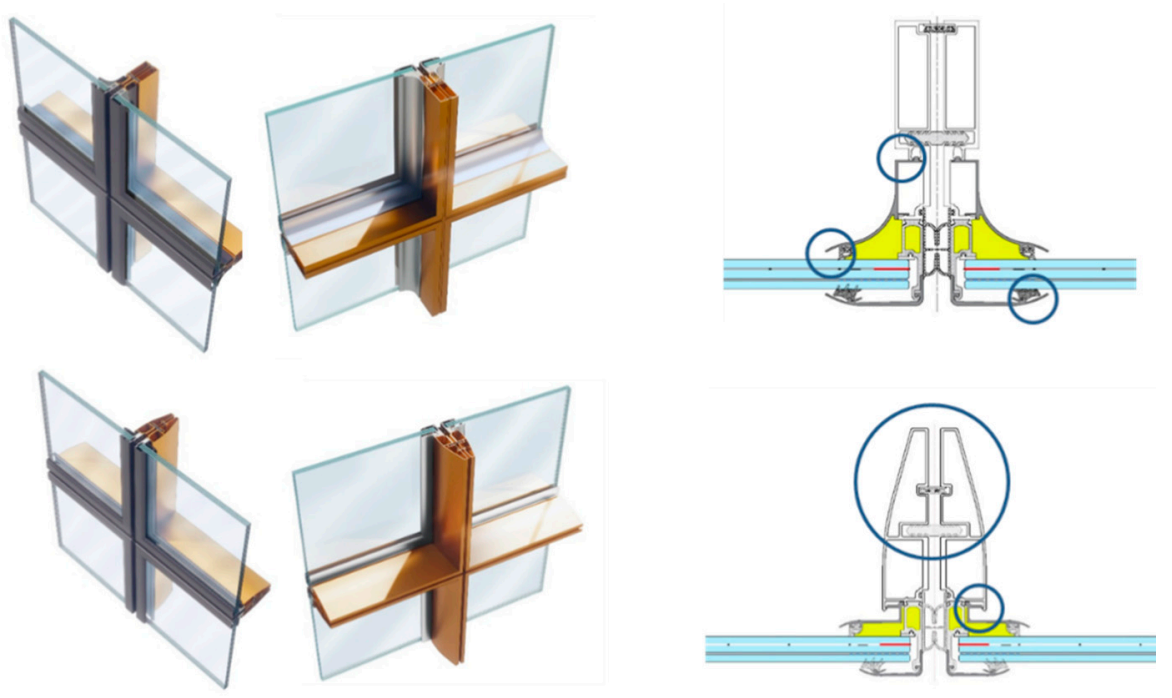

Figure 9. Architectural issues that emerged during the system design. Among the architectural aspects that emerged, some of them have been faced and adopted, while others have been dismissed for thermal and manufacturing reasons. 


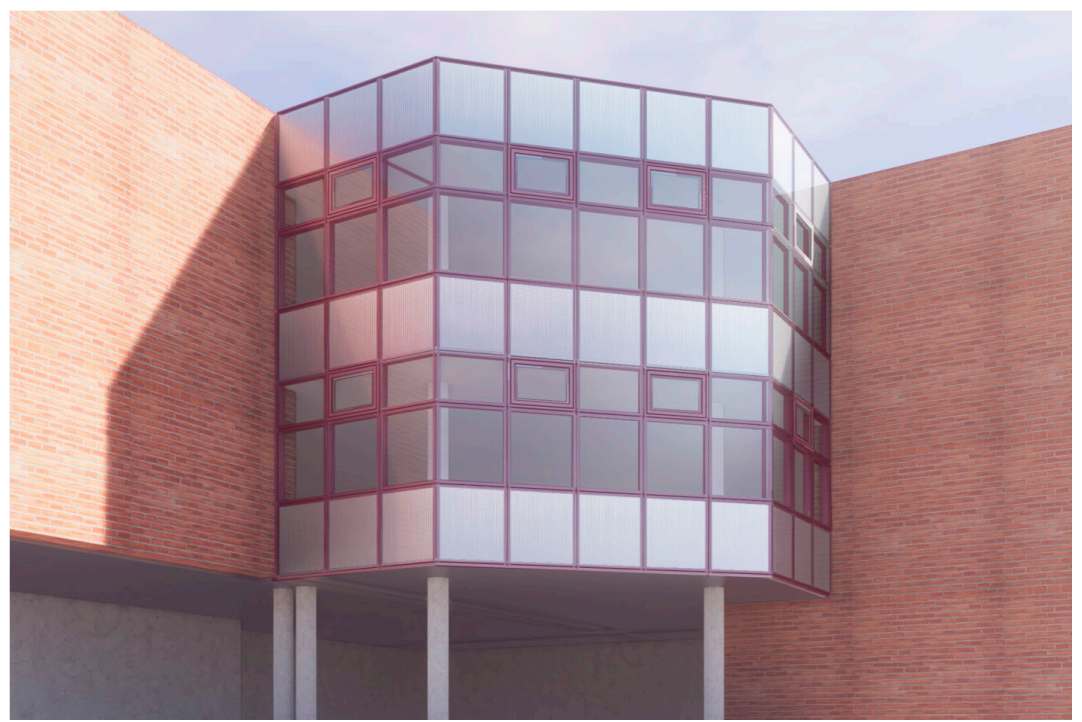

Figure 10. Dzierżoniów School color study with RAL 4001. Exterior view (credit: UNSTUDIO).

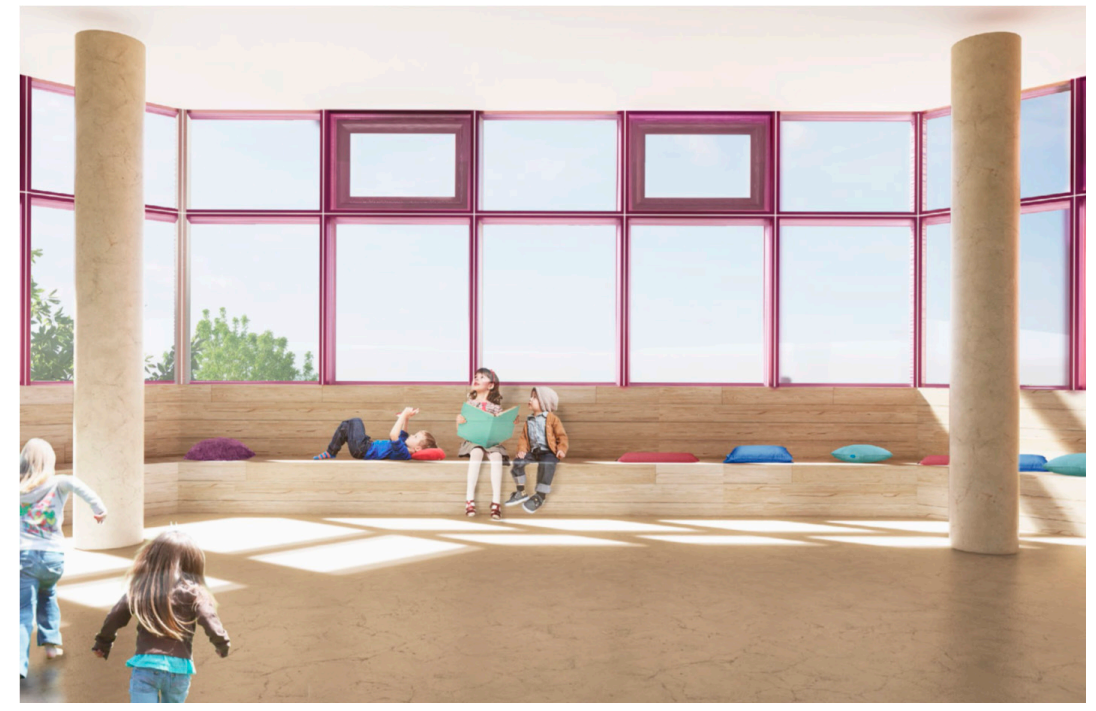

Figure 11. Dzierżoniów School: color study with RAL 4001. Interior view. (credit: UNSTUDIO).

\subsubsection{Market Benchmark and Replacement Strategy}

Another issue considered is the risk of failure of the VIG. Indeed, if the VIG developed in the Eensulate project is an innovative product of research, its behavior is still unknown. For this reason, it appears necessary to provide a replacement strategy for the building in case of failure of the VIG; TGU utilization in the Eensulate façade has been studied for this purpose. Indeed, TGU is the current market benchmark for VIG, offering the opportunity to compare the VIG performance with TGU, the direct competitor on the market. With some minor on-site interventions (cutting or replacement of the internal cover-cap), the Eensulate system should be adaptable for TGU installation in case of replacement.

\subsection{Eensulate Facade System: Final Design}

The present chapter presents the final design of the Eensulate façade system in Figure 12. On the base of the information collected during the intermediate investigations and analysis conducted, the Eensulate module integrates Eensulate components (foam and VIG) in a solution able to face the major key points that emerged. In particular, focusing on energy performance, the overall thermal 
transmittance of the Eensulate module is $0.64 \mathrm{~W} / \mathrm{sqm} \cdot \mathrm{K}$, in line with the expected target, even if more restrictive characteristics have been considered (unit dimension, glazing beads) (Table 5).
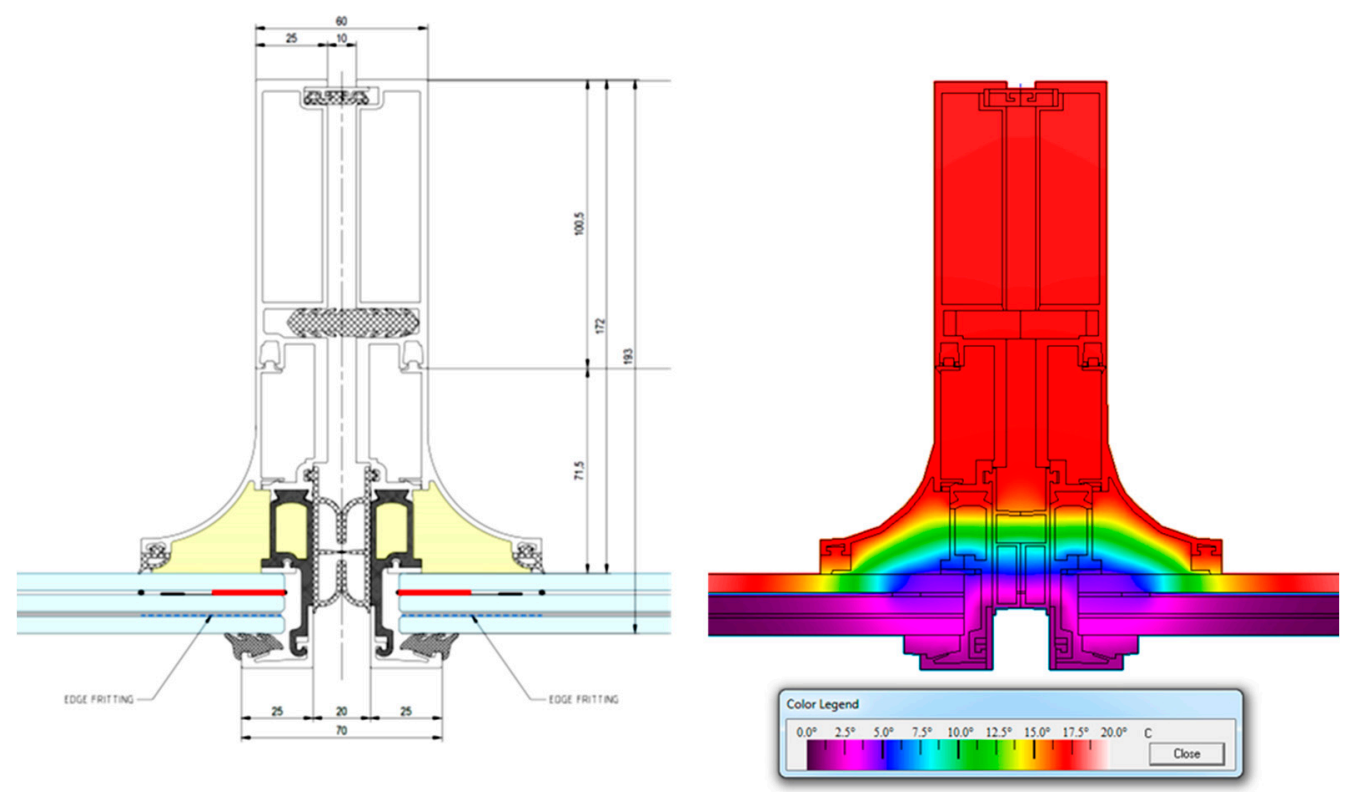

Figure 12. Eensulate module system design for the vision part.

Table 5. Eensulate facade system solution. Key points of the solution.

\begin{tabular}{cccc}
\hline Solutions Adopted & Issues Emerged & $\begin{array}{c}\text { Thermal Transmittance } \\
\text { Achieved }\end{array}$ & Target \\
\hline $\begin{array}{c}\text { Eensulate façade system } \\
\text { design finalized }\end{array}$ & Sealant to $25 \mathrm{~mm}$ & $0.64 \mathrm{~W} / \mathrm{sqm} \cdot \mathrm{K}$ & $\begin{array}{c}0.641 \mathrm{~W} / \mathrm{sqm} \cdot \mathrm{K} \\
\text { (sealant to } 25 \mathrm{~mm} \text { ) }\end{array}$ \\
\hline
\end{tabular}

The Eensulate façade system allows the replacement of VIG with TGU in case of failure (vacuum loss, breakage). The Figure 13 shows the Eensulate profile in case of installation of TGU. Even if VIG developed in Eensulate will fail (specific tests will be performed to validate its durability), replacement with TGU can support its adoption, going beyond market barriers based on VIG current market readiness.
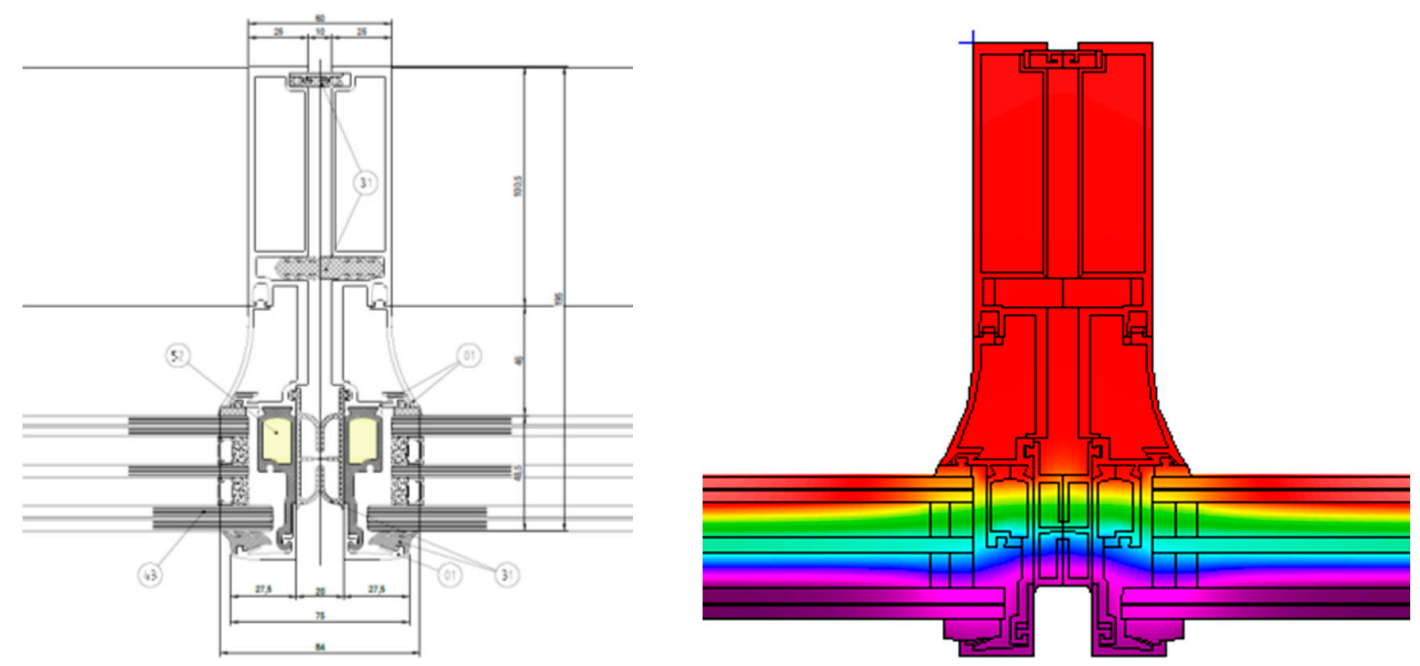

Figure 13. Eensulate facade system with TGU. In case of failure, VIG can be replaced with TGU installation with minor fixings needed on façade's cover-cap. 


\section{VIG Specifications}

In the scale up process of the VIG prototyped, aesthetic and safety considerations have also been included. Figure 14 shows the VIG sheet with specific aspects of the scale up faced, useful for integration in the Eensulate module and in the demo building of the reference. In particular, the following additional elements have been included:

- VIG lamination - the external glass pane is laminated to avoid falling risk in case of VIG breakage, meeting the safety specifications of public buildings;

- Fritted glass—sealant and getter design is a frame all around the VIG of $43 \mathrm{~mm}$ total (sealant $25 \mathrm{~mm}$, space between the sealant and getter $10 \mathrm{~mm}$, getter $8 \mathrm{~mm}$ ) that can have consequences on aesthetic of the glass. In order to minimize the visual effect of this frame, a gradient fritting has been adopted to reduce the visibility of the sealant and getter.

These VIG specifications are the reference for glass manufacturer procurement.

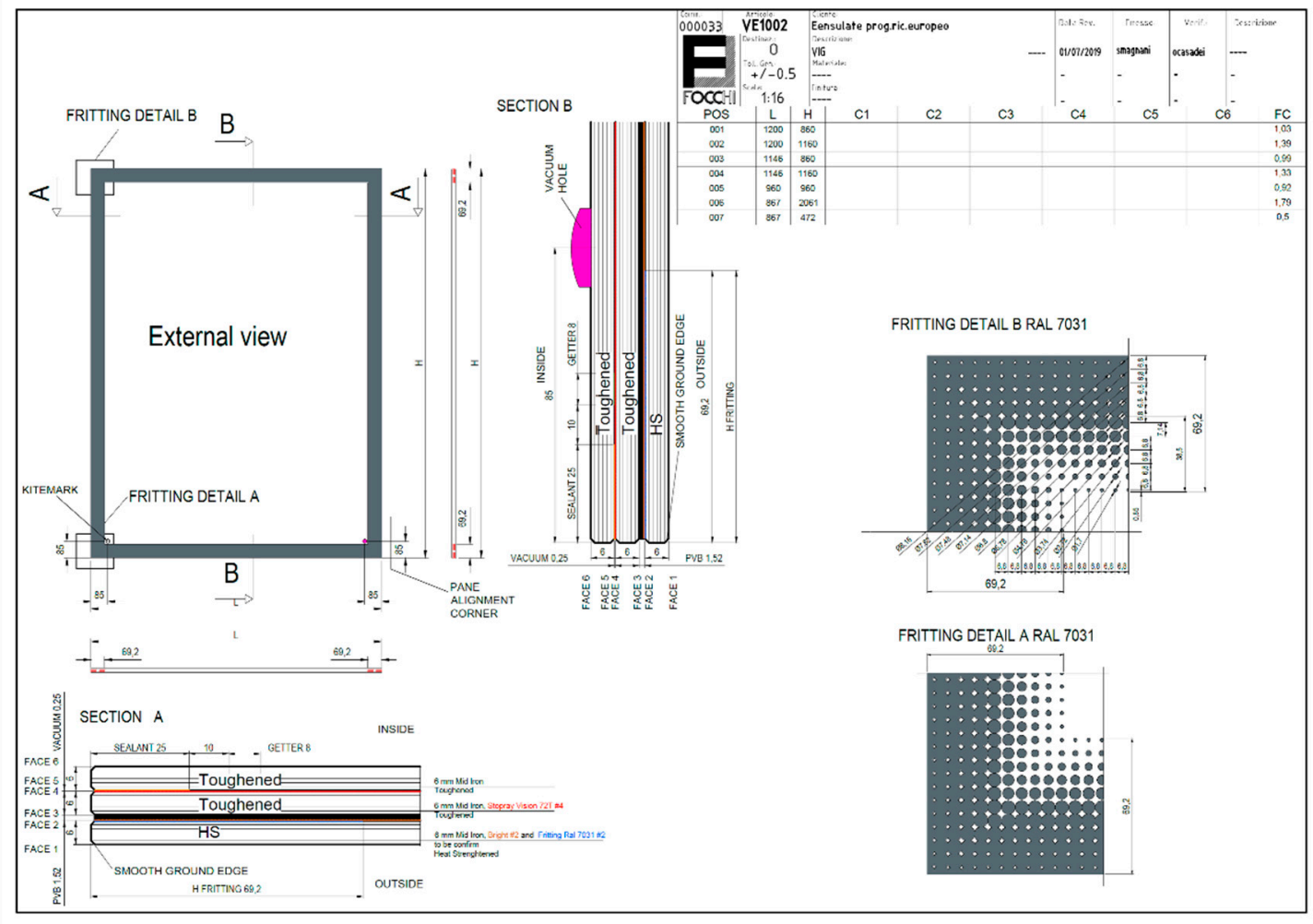

Figure 14. VIG sheet.

\section{Discussion}

The Eensulate façade system design has achieved its target for the design phase. The main achievements of the Eensulate system design are:

- Integration of innovative Eensulate components-both Eensulate foam and Eensulate VIG can be integrated in a façade solution. The parallel development of VIG and the Eensulate façade system design has allowed definition of the two products in a win-win strategy: on the one hand, VIG demonstrates its applicability in a unitized system; on the other, the curtain wall system keeps demonstrating the capability to integrate multiple components thanks to its prefabricated and high precise design.

- High energy efficiency of Eensulate module-the overall $U$-value of the Eensulate module $(1261 \times 3640 \mathrm{~mm})$ is $0.64 \mathrm{~W} / \mathrm{sqm} \cdot \mathrm{K}$, a significant step in relation to the market benchmark 
(the Eensulate façade's $U$-value with TGU is $0.77 \mathrm{~W} / \mathrm{sqm} \cdot \mathrm{K}$ ) with an estimate improvement of $16.8 \%$.

- New profiles definition - to integrate the VIG, new aluminum profiles with internal insulation and a new polyamide profile for thermal break have been identified.

- Valuable architectural aesthetic - the final aesthetic of the Eensulate module respects the architectural target for the curtain wall façade, allowing the personalization of some details (frame treatment, fritting), with some minor issues but which are architectural acceptable (curved cover-cap, fritting).

\section{Conclusions}

The results achieved in the Eensulate system design demonstrate how Eensulate components-foam and VIG in particular-can play an important role in the definition of a high-energy standard in building envelope, even in cases of buildings with large glass surfaces. Indeed, their integration in façade solutions has demonstrated the possibility of significant steps forward in the façade industry. The glass and aluminum façade market could deeply benefit from the introduction of VIG in the market, with remarkable decrease in overall energy performance together with a reduction in façade weight.

Despite the considerable achievements, there are some open issues to be faced in the next development phases:

- Tests-specific tests will be conducted to validate the façade and achieve the façade's CE certification with UNI EN 13830:2005, acoustic insulation (target is expected to be $52 \mathrm{~dB}$ ), and fire test in a furnace (in comparison with a benchmark solution).

In addition, some further developments are suggested as the output of this system design to keep improving the Eensulate components beyond the project:

- Sealant dimension - the sealant is a significant thermal bridge and its dimension is a challenging topic. Sealant dimension reduction is an important step to improve further the thermal transmittance of the façade with an impact on architectural issue binding at this moment (fritting and bright in VIG or curved cover-cap in profile).

Author Contributions: Conceptualization, O.C.; methodology, O.C. and A.P.; software, S.M.; validation, O.C., S.M. and A.P.; formal analysis, S.M.; investigation, O.C., S.M. and A.P.; resources, O.C., S.M. and A.P.; data curation, S.M.; writing—original draft preparation, A.P.; writing—review and editing, A.P.; visualization, A.P.; supervision, A.P. and O.C.; project administration, A.P.; funding acquisition, A.P. All authors have read and agreed to the published version of the manuscript.

Funding: This project has received funding from European Union's Horizon H2020 research and innovation programme under grant agreement No. 723868. H2020-EEB-2016-2017/H2020-EEB-2016.

Conflicts of Interest: The authors declare no conflict of interest. The funders had no role in the design of the study; in the collection, analyses, or interpretation of data; in the writing of the manuscript, or in the decision to publish the results.

\section{References}

1. European Commission. EUROPE 2020: A Strategy for Smart, Sustainable and Inclusive Growth 2010. Available online: https://eur-lex.europa.eu/legal-content/en/ALL/?uri=CELEX\%3A52010DC2020 (accessed on 12 August 2020).

2. European Parliament Directive 2010/31/EU of the European Parliament and of the Council of 19 May 2010 on the Energy Performance of Buildings 2018; European Parliament: Brussels, Belgium, 2018.

3. Mays, J.C. De Blasio's 'Ban' on Glass and Steel Skyscrapers Isn't a Ban at All. New York Times, 25 April 2019.

4. Schoenefeldt, H. Glass Skyscrapers: A Great Environmental Folly That Could Have Been Avoided. Available online: http://theconversation.com/glass-skyscrapers-a-great-environmental-folly-that-could-have-beenavoided-116461 (accessed on 12 August 2020). 
5. Epstein, S. Everyone Needs to Stop Building Giant Glass Skyscrapers Right Now. Available online: https://www.wired.co.uk/article/stop-building-glass-skyscrapers (accessed on 12 August 2020).

6. Building \& Industrial. Widest Range of Glass Solutions on the Market. Available online: https://www.agcglass.eu/en/products/building-industrial (accessed on 12 August 2020).

7. Welcome to Interpane! Available online: https://www.interpane.com (accessed on 12 August 2020).

8. Saint-Gobain Glass. Available online: https://www.saint-gobain-glass.com/ (accessed on 12 August 2020).

9. Glass Manufacturer, Glass Supplier in Europe | Guardian Glass. Available online: https://www.guardianglass. com/eu/en (accessed on 12 August 2020).

10. Fineo AGC Yourglass. Available online: https://www.agc-yourglass.com/it/it/brands/fineo (accessed on 12 August 2020).

11. Pilkington Spacia ${ }^{\mathrm{TM}}$. Available online: http://www.pilkington.com/en/global/products/product-categories/ thermal-insulation/pilkington-spacia (accessed on 25 January 2018).

12. LandVac Tempered Vacuum Insulated Glass-LandGlass. Available online: https://www.landglass.net/ LandVac.html (accessed on 12 August 2020).

13. AGC Glass Europe. AGC Glass Unlimited. Available online: https://www.agc-yourglass.com/sites/default/ files/brochures/original/yg_pocket_2014_fr.pdf (accessed on 1 September 2020).

14. AGC Clearsight. Enhance Your View with Anti-Reflective Glass. Available online: https://www.agcyourglass.com/sites/default/files/brochures/original/Clearsight_EN_LR.pdf (accessed on 1 September 2020).

15. Glass, R. Triple Glazing v Double Glazing. Available online: https://www.regencyglass.co.uk/faq-2/tripleglazing-v-double-glazing/ (accessed on 16 September 2020).

16. Home | Eensulate.eu. Available online: http://www.eensulate.eu//__possible_unsafe_site_ (accessed on 27 March 2018).

17. Progress | Eensulate.eu. Available online: http://www.eensulate.eu/progress (accessed on 13 August 2020).

18. UNSTUDIO-Site. Available online: http://www.unstudio.com/en/page/335/homepage (accessed on 13 August 2020).

(C) 2020 by the authors. Licensee MDPI, Basel, Switzerland. This article is an open access article distributed under the terms and conditions of the Creative Commons Attribution (CC BY) license (http://creativecommons.org/licenses/by/4.0/). 